\title{
K-2. Bipotentiality of Medulloblastoma
}

\section{Electron Microscope Observation of Brain Tumors and Changes Occuring in Vitro}

\author{
Teruhiko Okino, M. D., Yasuo Honda, M. D. \\ and Koichi Kitamura, M. D. \\ Department of Neurosurgery, Tokyo Women's Medical College \\ Leopold Liss, M.D. \\ Division of Neuropathology, The Ohio State University
}

The findings of medulloblastoma in electron microscopy is still obscure. Luse reported that the tumor was composed of two kinds of clear round cells and electron dense irregular cells in 1961. Recently, Wechsler-Zülch reported that the tumor was composed of only regular round cells ${ }^{1}$. Besides, medulloblastoma is often hardly diagnosed differentially from sarcoma on light microscope. We have applied electron microscopy for the morphological approach to observe brain tumors and changes during occuring the maintenance in vitro.

The first case showed only a kind of tumor cells and electron micrographs revealed almost the same characteristic findings as reported by Wechsler-Zülch except imcomplete desmosomes and/or incomplete neuronal junctions. Those were matured to complete desmosomes in vitro within 3 weeks and newly Golgi apparatus and centriole appeared in the site of free surface of tumor cells. The cytoplasmic organelles were increased in number and microtubuli were also newly seen. Those findings mean that medulloblastoma of surgical tissue differentiated to ependymal line in vitro.

The second case was diagnosed as medulloblastoma with regular hematoxylineosin stain but silver impregnation showed sarcomatous pattern. The electron micrographs revealed two kinds of clear round cells and electron dense irregular cells. The findings were the same as Luse reported in 1961. There were no collagen fibers between tumor cells, which is thought to be characteristic in sarcoma by Wechsler-Zülch.

Fujita observed neuronal differentiation of medulloblastoma with tissue culture on light microscope. There has been no report that the bipotentiality of medulloblastoma was confirmed by electron microscopy. But we confirmed the ependymal differentiation of medulloblastoma with tissue culture on electron microscope in the first case.

\section{References}

1) Zülch, K. J. and Wechsler, W.: Krayenbühl et al.: Progress in Neurological Surgery,

2) Russell, D. S. and Rubinstein, L. J.: Pathology of Tumors of the Nervous System, 3rd ed. p. 186, 1971. 